\title{
UMA ANÁLISE DA RELAÇÃO DO PRECONCEITO COM A COMPREENSÃO EM GADAMER
}

\author{
An analysis of the relationship of prejudice with understanding in Gadamer
}

CESAR AUGUSTO SILVA DE SOSA ${ }^{1}$

RITA DE CASSIA OLIVEIRA ${ }^{2}$

\section{Resumo}

Sempre estamos imersos em uma determinada tradição que nos influencia, ela jamais deve ser tida como verdadeira sem antes ser submetida ao juízo da razão, mas essa razão não tem autoridade para liquidar a tradição, ela não pode ser simplesmente descartada como queriam os filósofos das luzes entre os séculos XVII e XIX. Portanto, ao tratar do preconceito em Gadamer é justamente retomar o que deve ser aproveitado da tradição para fundamentar o "novo". Contudo, partimos de uma análise do que é preconceito para o filósofo Gadamer, com o intuito de chegar a uma relação dele com o ato de compreender e, a partir daí, saber o que devemos fazer para estar abertos para a construção do novo.

Palavras-chaves: Análise do preconceito; Filosofia Contemporânea; Hermenêutica;

\begin{abstract}
We are always immersed in a certain tradition that in fluences us, it must never be taken as true without first being subjected to the judgment of reason, but this reason has no authority to settle tradition, it cannot simply be dismissed as the philosophers of light wanted. between the seventeenth and nineteenth centuries. Therefore, when dealing with prejudice in Gadamer, it is precisely to take back what must be used by tradition to support the "new". However, we start from an analysis of what is prejudice for the philosopher Gadamer, in order to come to a relationship between him and the act of understanding and from that know what we must do to be open to the construction of the new.
\end{abstract}

Keywords: Prejudice analysis; Contemporary philosophy; Hermeneutics;

\section{INTRODUÇÃO}

Ao nos perguntarmos como acontece a atitude da compreensão, nos deparamos com o filósofo Hans-Georg Gadamer (1900-2002). Ele é considerado uma figura de imprescindível importância para o desenvolvimento da hermenêutica, e a partir de sua teoria filosófica podemos caminhar em busca de entendermos como acontece a compreensão humana. Gadamer influenciado pelo pensamento heideggeriano, retoma a descrição do círculo hermenêutico

\footnotetext{
${ }^{1}$ Estudante de Graduação de Licenciatura em filosofia - Universidade Federal do Maranhão - UFMA casscesar2@gmail.com

${ }^{2}$ Doutora em Filosofia - PUC-SP e professora da Universidade Federal do Maranhão - UFMA rcoliveira30@yahoo.com.br
} 
(GADAMER, 2014, p. 355), no qual, é relevante perceber que na tentativa de compreender algo, sempre existe o risco de que o sujeito pode ficar preso nas suas próprias intuições prévias.

Dessa forma, para evitar esse risco, deve-se ter um limite que permita que o sujeito não se deixe levar sempre por seus preconceitos, ou seja, nós não poderemos nem os descartá-los por completo, nem nos tornar um prisioneiro deles. Nesse sentido, ao contrário do que aconteceu no século XVIII e XIX com o iluminismo, Gadamer estava preocupado em não negar a tradição, ele queria, talvez, até valorizá-la, pois, a tradição é justamente o que temos como a mais fundamental base para a compreensão do mundo, e é somente por meio dela que podemos superá-la, portanto, entende-se que o desenvolvimento só e possível pela consideração à tradição.

Para Gadamer, por tradição podemos ter em mente ao menos dois sentidos, um como conservação e o outro como transmissão. Esses dois sentidos asseveram que não podemos ignorar as verdades que estão contidas no seio das culturas. Para tanto, não há como eliminar a tradição, pelo menos ela é algo que está imersa no sujeito sempre que buscamos entender algo, pois, nós nunca estamos partindo do zero, mas de nossos julgamentos prévios.

O problema se encontra quando nos fechamos neles e nos tornamos incapazes de submeter esses julgamentos à uma avaliação que permita deixá-los, caso seja necessário, como comenta Zabeu:. "O horizonte de compreensão do existente humano, [...] encontra-se sempre situado historicamente, permeado por preconceitos que se instauram com certa autoridade por tradições" (ZABEU, 2014, p. 41). Nesse sentido, a problemática da compreensão se dá em uma realidade histórica, pois, é a ideia de tradição, no qual o sujeito se encontra totalmente imerso, que é responsável por construir os chamados preconceitos, e só são a partir desses dois sentido de tradição, que é possível começar surgir o entendimento.

\footnotetext{
Naturalmente que o sentido somente se manifesta porque quem lê o texto lê a partir de determinada expectativa e na perspectiva de um sentido determinado. A compressão do que está posto no texto consiste precisamente na elaboração desse projeto prévio, que, obviamente, tem que ir sendo constantemente revisado com base no que se dá conforme se avança na penetração do sentido (GADAMER, 2014, p. 356).
}

Apesar de o entendimento só surgir através da tradição e do preconceito, o sujeito deve sempre estar em uma autoavaliação, pois, só assim ele coloca em jogo suas intuições prévias e pode estar aberto à compreensão de novas possibilidades tanto de um texto, como a citação acima mostra, quanto do mundo a sua volta. Logo, é claro que temos preconceitos, e é impossível escapar deles quando estamos tratando da nossa capacidade de reflexão e de entendimento. Quando buscamos entender, já estamos imersos em um conjunto de experiências individuais, que foi construído historicamente e pelas razões sociais em que o sujeito está. 
O modo de como se dá o conhecimento a partir de uma abertura para o novo, se vale de uma densa reflexão, e chamamos de novo aqui, as novas compreensões, ou perspectivas do mundo, para evitar assim o "círculo hermenêutico", no seu fechamento no preconceito. Para tanto, sabemos que somos guiados por concepções prévias e que essas são embasadas em uma determinada cultura, e isso se relaciona com o modo em que compreendemos o mundo.

Tratamos então de distinguir os preconceitos que são inadequados dos adequados para tal feito, demonstrando a importância desse tipo de preconceito e como eles permitem a possibilidade para a constituição do novo. Dessa forma, tratar do preconceito em Gadamer é justamente retomar o que deve ser aproveitado da tradição para fundamentar esse diferente mundo fora dos nossos preconceitos. Então, partimos de uma análise do que é preconceito para o filósofo Gadamer, com o intuito de chegar a um esclarecimento a respeito do ato de compreender.

\section{O QUE SE ENTENDE POR PRECONCEITO}

O termo preconceito em Gadamer não tem a forma pejorativa que está presente no nosso século, terá um sentido muito mais voltado para o seu lado literal, isto é, de um pré-juízo ou uma pré-compreensão. Sendo assim, ele vai tratar esse termo nem como negativo, nem como positivo, mas como algo que não podemos fugir, uma vez que é essa categoria faz parte de como o nosso conhecimento é produzido, dando as condições básicas que estabelece o processo hermenêutico para se atingir a compressão, pois, antecedem as condições do entendimento.

[...] Muitos, porém, têm uma visão em sentido negativo sobre o que venha ser preconceito, e isso pode vir a interferir quando somos indagados sobre tal concepção. Vemos, em nossos dias, que quaisquer formas de preconceitos, sejam eles religiosos, étnicos, raciais, sociais, econômicos, etc., são considerados crimes, e quando praticados, implicam penalidade. Ao analisarmos o que Gadamer entende por preconceito, poderemos ter uma visão mais ampla nesse sentido. (FRISON, c2017, p. 03).

Esse termo pode ser entendido tanto como por um preconceito da estima humana, marcado assim, por uma tradição e uma cultura sem que tenha a característica de te engessar, no entanto, o termo também tem o aspecto de uma precipitação, ou seja, de uma intuição grosseira. Dessa forma quando queremos nos referir aos preconceitos marcados pela sua relação com a tradição, ou seja, a chamaremos de Autoridade, cujo qual, Gadamer ira voltar sua atenção, onde julga como um aspecto que serve de fundamento para o entendimento, isto é, são validos, já a intuição grosseira é um julgamento precipitado que não permite uma abertura para o novo, para tanto devem ser superados por não serem validos.

O sentido pejorativo do termo tomou esse significado em grande parte por influência dos iluministas, que viram na tradição um obstáculo para o uso da racionalidade, que tanto se almejava 
no século das luzes. Dessa forma, buscava-se a libertação do homem das amarras da igreja, para tanto, há o descarte de toda a tradição por parte do movimento iluminista, começando a existir então um "preconceito contra os preconceitos, em geral, e com isso, a des-potencialização da tradição" (GADAMER, 2014, p. 360).

Para o homem chegar ao progresso, ele devia renunciar a sua tradição, suas crenças e dogmas, ou seja, pretendiam dissipar a tradição, que em resumo seria a própria religião cristã, que para eles, era um dos principais obstáculos para o avanço humano. Eles se preocupavam em não aceitar nenhuma verdade preestabelecida, rejeitando a ideia de que o homem seja um sujeito histórico. Ao contrário, Gadamer acreditava que é impossível estarmos isentos dos preconceitos, já que não se pode avançar para o novo sem antes termos uma pré-compreensão que possa dar sentido ao nosso desenvolvimento.

A Aufklärung quis fundamentar tudo na razão, e fez dela um método para alcançar seus ideais, contudo, se esqueceu de que não se pode fazer uma investigação partindo do zero, sem noções que sejam prévias. Quando se busca algo, é pelo fato de se ter sido impulsionado anteriormente. (FRISON, c2017, p. 07).

O preconceito, significa, como foi dito antes, um juízo que se forma antes que a razão possa estabelecer sua veracidade, porém, isso não significa de forma alguma que o juízo seja falso, mas que tem a possibilidade ser, sendo assim o "seu conceito permite que ele possa ser valorizado positiva ou negativamente" (GADAMER, 2014, p. 360) e quem vai decidir isso é o indivíduo a medida em que analisar pela sua razão a sua pré-compreensão, que pode ser concretizado como verdadeiro ou não.

\section{A IMPORTÂNCIA DA PRÉ-COMPREENSÃO}

Como vimos, a neutralidade é impossível, pois, não se pode abrir mão do passado como queria o iluminismo, pois, não existe um sujeito fora da história, já que isso faz parte de sua realidade. Sendo assim, o uso da razão livre de juízos prévios, como um único método para se chegar ao entendimento se mostra inviável para o ser humano. Para Zabeu, Gadamer busca reconhecer então, na tradição e no pré-juízo, já que esses podem ser produtivos para o pensar e o agir humano, no aspecto histórico que permeia sua vivência.

O que pode ser dito é que enquanto os preconceitos ilegítimos, de certo modo, podem encobrir o fenômeno, o ser em sua manifestação, isto é, a verdade do tema a que se refere o preconceito, estreitando o horizonte de compreensão do existente humano; os preconceitos legítimos, por sua vez, podem revelar, desocultar a verdade, trazer o fenômeno da tradição à luz, ampliando seu horizonte compreensivo (ZABEU, 2014, p. 25) 
Para tanto, os preconceitos de autoridade de Gadamer é o fundamento à compreensão, assim para ele o compreender "não pressupõe nem uma "neutralidade" com relação à coisa nem tampouco um anulamento de mesma; implica antes uma destacada apropriação de opiniões previas e preconceitos pessoais" (GADAMER, 2014, p. 358). É pela experiência histórica e individual que o homem buscar perguntar sobre a validade ou não de algo, esse é o motivador para ir atrás de novas respostas e perguntas diversas, principalmente se o problema é histórico e permeia sua cultura, portanto, partindo de um diálogo com sua tradição ele até pode estar permeado por visões previas, no entanto, isso não impede a abertura para outras compreensões.

Os clássicos são as tradições que em momentos de desenvolvimentos culturais, conseguiram resistir ao tempo, se tornando assim atemporais, através de registros documentais ou memoriais. Nesse sentido, não há apenas uma retomada, mas uma apropriação desses problemas, para que haja uma elevação e uma superação deles, a partir de um constante questionamento que nos leva a uma nova perspectiva, ou seja, um novo olhar sobre aquele dado problema.

Isso ocorre sobretudo nas ciências do espírito que contam com uma tradição antiga. A ciência clássica da Antiguidade, por exemplo, depois de ter elaborado a mais vasta abrangência de sua própria tradição, voltou-se sempre de novo, com questionamentos cada vez mais afinados, para os velhos objetos prediletos de sua ciência. (GADAMER, 2014, p. 378).

Logo o que possibilita o conhecimento é a tradição, justo que, é aquilo que permanece e serve de base para a posteridade na forma dos "clássicos". A distância temporal permite mostrar quais os preconceitos que são de autoridade e que podem conduzir para a compreensão e para uma abertura de novos conhecimentos. O preconceito não pode mais ser visto apenas como um entrave, mas ao contrário deve haver um reconhecimento dos preconceitos verdadeiros, que contribuem e tem utilidade, para o ser humano.

\section{A ABERTURA PARA NOVAS POSSIBILIDADES}

A categoria de preconceito é muito mais do que somente um pertencimento a história, pois, a gama de conhecimento não pode está determinada por essas intuições, o homem deve ir além delas. Não se tem a "consciência como pura intuição" (CROCOLI, 2012, p. 45), mas com uma fusão de horizontes, isto é, a relação entre o passado, presente e futuro, utilizando do passado como uma base que fundamenta as decisões do presente que irão visar o futuro, a partir de como é influenciado pela sua tradição e com o aparecimento de perguntas.

Quando se ouve alguém ou quando se empreende uma leitura, não é necessário que se esqueçam todas as opiniões previas sobre seu conteúdo e todas as opiniões próprias. O que exige é simplesmente a abertura para a opinião do outro ou para a opinião do texto. Mas essa abertura implica sempre colocar a opinião do outro em alguma relação com o 
conjunto das opiniões próprias, ou que a gente se ponha em certa relação com elas. (GADAMER, 2014, p. 358).

A partir da citação, observamos que Hans-Georg Gadamer não rejeita as opiniões prévias, mas defende que toda a possibilidade de abertura para o novo está de alguma forma relacionada com as próprias opiniões prévias. O preconceito serve de base e de fundamento para que o ser humano crie um sentido naquilo que está observando no mundo, pois, é somente a partir disso que ele cria suas expectativas e busca compreender aquilo que desconhece. Com isso é possível estabelecer a veracidade dos preconceitos, pois, se as expectativas forem atendidas, isso significa que os juízos prévios se concretizaram.

O preconceito de autoridade se dá no reconhecimento de que estamos em uma tradição, e que aceitamos que a preconcepção pode ser um fundamento para algo. Isso não deve ser levado a uma cegueira com uma completa sujeição, por esse motivo, devemos estar acompanhados pela nossa faculdade de raciocínio, que nos servirá de guia. Com isso podemos analisar o preconceito de maneira a não o descartar a menos que se comprove que ele era equivocado.

Não existe purismo, ou seja, não tem uma submissão completa a razão. Ao contrário, o que existe é uma investigação, que nos permite ir atrás das respostas para um problema que surgiu no horizonte do desconhecido, em que nunca abandonamos a carga de conhecimentos que obtivemos previamente. Ao falar que não existe um purismo, significa mostrar que o ser humano ao fazer a escolha para investigar algo, ela está diretamente relacionada à sua tradição, história, e também seus preconceitos.

Inovar é, portanto, exatamente isso, não se trata necessariamente de criar algo novo do zero, coisa que ao analisarmos profundamente, veremos ser quase impossível, mas sim dá um novo olhar. Sendo assim, os novos problemas sempre ressoam dos velhos, as novas problemáticas que surgem são novas perspectivas dos antigos, que podem ser resolvidos a partir daquilo que temos como conjunto de conhecimentos da onde estamos inseridos.

O que satisfaz nossa consciência histórica é sempre uma pluralidade de vozes que ressoa o passado. O passado só aparece na diversidade dessas vozes. É isso que constitui a essência da tradição da qual participamos e queremos participar a própria investigação histórica moderna não é só investigação, mas também mediação da tradição. (GADAMER, 2014, p. 377).

\section{O PROBLEMA DO PRECONCEITO}

A tarefa crítica da Hermenêutica será compreender o fenômeno da distância temporal e o esclarecimento do seu conceito, ou seja, distinguir os preconceitos que cegam daqueles 
que esclarecem. Questão que supõe uma análise da consciência da histórica dos efeitos como estrutura da experiência (SILVA \& LOPES, 2014, p. 03).

Contudo, entendemos que não existe nenhuma forma de pensar em compreender algo, sem que tenha alguma relação com nossos juízos prévios, sendo eles negativos ou positivos. E a abertura para os novos conhecimentos dependem unicamente de não cairmos no círculo vicioso dos preconceitos negativos, isto é, os juízos que além de não nos acrescentarem nada, nos impedem de ir além do horizonte do desconhecido. Sendo assim, isso resume o problema que se encontra o preconceito por precipitação.

"Aquele que quer compreender não pode se entregar de antemão ao arbítrio de suas próprias opiniões prévias, ignorando a opinião do texto da maneira mais obstinada e consequente possível" (GADAMER, 2014, p. 358). A partir desse fragmento, podemos observar que deve haver uma atenção quando estamos lidando com nossos preconceitos. Nesse sentido, não podemos simplesmente aceitá-los sem que haja uma análise profunda desses.

As crenças e dogmas que aprendemos da nossa cultura, e o conhecimento histórico que carregamos, se não tomados com cuidados podem engessar o entendimento, e abertura para a investigação à procura de inovação, podem se tornar inviáveis. Por conta disso o iluminismo de forma errônea tentou eliminar a tradição. No entanto, apesar de os problemas com o preconceito e do que eles podem acarretar, isso não invalida "o fato de que ela pode ser também uma fonte de verdade" (GADAMER, 2014, p. 370).

\section{CONSIDERAÇÕES FINAIS}

O conceito de preconceito, trata-se de um tema com uma fundamental importância para a discussão de como compreendemos o mundo, a partir dele se abre uma possibilidade para os diversos outros tipos conhecimentos, se colocados de maneira correta. E é justamente isso que retiramos dos textos de Gadamer, contudo, tratamos de relembrar o conceito de preconceito que foi adquirindo por ele, demonstrando assim, que apesar de a maioria ver esse termo de forma negativa, devido a vários fatores, não podemos esquecer que eles são a base do ato de compreende.

Logo, existem preconceitos que são de fatos legítimos, onde, só estamos abertos para algo novo, justamente porque conseguimos nos fundamentar em algo que já conhecemos. É através dos textos de Gadamer que podemos estar atentos a essa clara distinção entre os preconceitos de autoridade e os de precipitação, no qual entendemos a real importância deles e sua diferença. Contudo, entendemos que para construir o novo não se deve descartar nossa tradição histórica, mas que a cultura e nossos valores servem para essa construção, isto é, para a inovação e criação. 


\section{REFERÊNCIAS}

CROCOLI, D. J. Hermenêutia e educação: o movimento da compreensão em Gadamer. Dissertação (Educação), UNIVERSIDADE DE CAXIAS DO SUL, 2012.

FRISON, M. F.. Gadamer e o pre-conceito. Diritto straniero, 2017.

GADAMER, H.-G. Verdade e Metodo I, Trad. F. P. Meurer, 14 ed. Petropoles, RJ: Vozes, 2014.

SILVA, A. F., \& LOPES, M. d. Experiência hermenêutica em Gadamer: da reabilitação dos preconceitos ao conceito de experiência hermenêutica. PERI, V 06, 2014.

ZABEU, G. M. Preconceito e Diálogo: Ética e Ontologia na Fusão de Horizontes. Dissertação (Filosofia), Universidade Federal de Santa Catarina, Florianópolis, 2014. 